\title{
Knowledge on neoplastic diseases among young rural inhabitants
}

\author{
Anna Lewandowska', Rafał Filip ${ }^{2}$ \\ 1 Institute of Healthcare, Bronisław Markiewicz State School of Technology and Economics, Jarosław, Poland \\ 2 Department of Clinical Endoscopy, Institute of Rural Health, Lublin, Poland
}

Lewandowska A, Filip R. Knowledge on neoplastic diseases among young rural inhabitants. Ann Agric Environ Med. $2017 ; 24(3)$ : 496-501. doi: $10.5604 / 12321966.1235158$

\begin{abstract}
Objective. The objective of the study was to analyze the level of knowledge on tumours and their prevention among rural inhabitants.

Materials and method. The research involved 500 residents of villages in Podkarpackie Province in south-east Poland. The age of the researched ranges from 18-30 years; mean age - 26.96 0.84 (range [18, 30], median 25.95\% Cl [18, 9, 29, 01]). The researched group was represented in $47.59 \%$ by women in $52.41 \%$ by men. In order to obtain the research material, a standardized questionnaire was applied which included questions focused mainly on assessment of the level of knowledge on tumours (causes, symptoms, ways of treatment, prevention), as well as questions with both spontaneous and prompted answers.

Results. $34.72 \%$ of respondents confirmed the occurrence of tumours in their family; the most frequently occurring was a lung tumour (9.4\%). While assessing the degree of relationship it was proved that among parents' of the respondents, neoplastic disease had occurred in $3.22 \%$ of cases, and in $22.36 \%$ of cases it affected grandparents. In self-assessment, a low level of knowledge was indicated by $35.35 \%$ of respondents: average by $30.45 \%$, hard to determine by $32 \%$, while $2.18 \%$ stated that their level of knowledge was high. The most frequently enumerated risk factors were: smoking (36.61\%), improper diet (15.03\%), and improper lifestyle (9.83\%). UV radiation was a risk factor for $16.18 \%$; however, a solarium only for $1.93 \%$ of respondents. For $37.94 \%$, a medical examination was a diagnostic method in neoplastic disease.

Conclusions. According to self-assessment, every third respondent stated having a low or average level of knowledge. The most frequently used source of knowledge was the Internet, and much more rarely a doctor or a nurse. Very few of the respondents could enumerate the tests applied in the early detection of neoplastic diseases.
\end{abstract}

\section{Key words}

neoplastic diseases, knowledge

\section{INTRODUCTION}

Despite the obvious positive changes brought by the development of civilization, technical, economic, and industrial progress, they have also become the reason for disorders of the internal homeostasis of organisms due to the continuous influence of various harmful external factors connected to civilization development. At every stage of life, from conception to adulthood, human beings are exposed to exhaust fumes, pesticides, detergents used in households, cosmetic agents, medicines or biological factors that are responsible for malignant transformation of cells, thus the formation of tumours due to civilization development.

Neoplastic diseases have been classified as civilization diseases and, according to the WHO report of 2003, tumours will be the greatest danger $21^{\text {st }}$ century. It is predicted that within the first decade of the current century one in every 900 adults aged 18-44 years will be a convalescent after a neoplastic disease from childhood $[1,2,3,4]$. Cancer is the second frequent cause of death (after poisoning and accidents) in children over 1 year old, while among people aged 65 and over, the second frequent cause of death accounts for $22.5 \%$ of deaths in this age group $[5,6]$.

\footnotetext{
Address for correspondence: Anna Lewandowska, Czarnieckiego 16, 37-500 Jarosław, Poland

Tel.: 698757926

E-mail: am.lewandowska@poczta.fm

Received: 11 March 2014; accepted: 13 November 2015; first published: February 2017
}

Technical development and modern methods of research do not prevent the increasing cancer problem, which is why prevention is extremely important, especially primary prevention. Primary prevention aims at decrease of cancer incidence and mortality by eliminating or reducing exposure to risk factors and the promotion of protective factors $[7,8]$. More than $80 \%$ of tumours are connected to lifestyle, which is why health behaviours are extremely important in the prevention of neoplastic diseases, and are a significant part of preventive measures. Pro-health behaviours are influenced by pro-health knowledge and use of this knowledge in everyday life as well as effective motivation. The promotion of prohealth behaviours should also especially concern women at child-bearing age, pregnant women, and finally, parents of all children, not only of those children in which anomalies were diagnosed after birth $[9,10,11]$. Knowledge of risk factors leading to neoplastic disease enables people to take preventive measures that must involve the whole of society to bring about a measurable and intended effect. These preventive measures should be planned for the period of a few decades and should be consistently executed throughout the whole period. Without such determination in execution, it will never be possible to pursue preventive measures [7].

\section{OBJECTIVE}

The objective of the study was to analyze the level of knowledge about tumours and their prevention among rural inhabitants. 


\section{MATERIALS AND METHOD}

The research involved 500 residents of villages in the Podkarpackie Province of south-east Poland. The age of the researched ranged from 18-30 years; mean age $26.96 \pm 0.84$ (range [18.30], median - 25.95\% CI [18.9; 29.01]). The researched group was represented in $47.59 \%$ by women and in $52.41 \%$ by men. Preparation and performance of the research lasted from 2007-2012.

In order to obtain the research material, a standardized questionnaire was applied which included questions focused mainly on the assessment of the level of knowledge about tumours (causes, symptoms, ways of treatment, prevention), and questions both to spontaneous and prompted answers.

Statistical analysis. All the statistical calculations were performed using data analysis software system STATISTICA developed by StatSoft, Inc. (2011), version 10.0. (www.statsoft. com., statistical package R version 2.15.1), and Microsoft Excel spreadsheet. Quantitive variables were characterised by arithmetic mean, standard deviation, median, minimum and maximum value (range), and 95\% CI (confidence interval). Qualitative variables have been presented by use of cardinality and percentage value. In statistical analysis, the following tests were applied: Shapiro-Wilk, Levene, Brown-Forsythe, Student's t-distribution, Mann-Whitney U, ANOVE F-test, and Kruskal-Wallis.

\section{RESULTS}

In the group of researched women, $4.62 \%$ had primary education, $33.91 \%$ vocational education, $46.44 \%$ secondary education, and $15.03 \%$ higher education. Among the men, $4.82 \%$ had primary education, $49.90 \%$ vocational education, $35.45 \%$ secondary education, and $9.83 \%$ higher education. The research attempted to determine whether the family of the researched group has experienced a neoplastic disease. According to the data analysis, $34.72 \%$ of respondents claimed that tumours had occurred in their family: $43.24 \%$ of women and $26.2 \%$ of men. Statistically significant differences in frequencies were proved by Fisher's 2-sided exact test $(\mathrm{p}<0.0001)$ that neoplastic disease occured more frequently in families of the researched women. According to $12.06 \%$ of women and $6.74 \%$ of men, the most frequent was lung tumour (9.4\%). Statistically significant differences in frequencies were also proved by Fisher's 2 -sided exact test $(\mathrm{p}=0.0045)$. Another frequent tumour was breast cancer (5.25\%), indicated by $9.15 \%$ of women and $1.35 \%$ of men. Statistically significant differences in frequencies were proved by Fisher's 2-sided exact test $(\mathrm{p}<0.0001)$. The occurrence of leukaemia in the families of respondents was declared by $0.93 \%-1.46 \%$ of women and $0.39 \%$ of men. The incidence of melanoma was stated by $1.01 \%$ of all respondents $-1.25 \%$ of women and $0.77 \%$ of men. $1.31 \%$ of respondents mentioned colorectal cancer $-1.46 \%$ of women and $1.16 \%$ of men. Statistically significant differences in frequencies were proved by Fisher's 2 -sided exact test $(\mathrm{p}=0.0012)$. The incidence of bone tumours in the families was confirmed by $1.4 \%$ of respondents $1.87 \%$ of women and $0.96 \%$ of men. Statistically significant differences in frequencies were proved by Fisher's 2-sided exact test $(\mathrm{p}=0.029)$. Laryngeal cancer was reported only by $1.01 \%$ of respondents $-1.25 \%$ of women and $0.77 \%$ of men.
Brain tumour occurred in respondents' families in $1.01 \%$ $1.25 \%$ of women and $0.77 \%$ of men. The researched group also reported the incidence of adrenocortical carcinoma in their families (0.19\%). Renal cell carcinoma occurred in $0.39 \%$ of respondents' families and prostate cancer in $1.16 \%$. The incidence of cervical cancer in the families was mentioned by $1.22 \%$ of all respondents $-1.66 \%$ of women and $0.77 \%$ of men. Pancreatic cancer was declared by $0.19 \%$ of female respondents, liver cancer occurred with a frequency of $1.30 \%$, both in women (1.25\%) and in men (1.35\%). Stomach cancer was mentioned by $1.18 \%$ of respondents $-0.83 \%$ of women and $1.54 \%$ of men.

While assessing the degree of relationship it was proved that among parents' of the respondents, cancer occurred in $3.22 \%, 3.74 \%$ of women and $2.7 \%$ of men. In $22.36 \%$ of cases, the tumour affected the grandparents $-29.11 \%$ of women and $15.61 \%$ of men. Statistically significant differences in frequencies were proved by Fisher's 2-sided exact test $(p<0.0001)$. Respondents also indicated the incidence of tumours in other relatives, aunts and uncles (9.75\%) - 13.72\% of women and $5.78 \%$ of men. Tumours in extended families accounted for $4.47 \%, 6.24 \%$ of women and $2.7 \%$ of men. Statistically significant differences in frequencies were proved by Fisher's 2 -sided exact test $(\mathrm{p}=0.0081)$. Very rare incidences of tumours was reported in siblings (0.39\%).

According to self-assessment, a low level of knowledge was indicted by $35.35 \%$ of respondents: average $-30.45 \%$, hard to determine $-32 \%$, high $-2.18 \%$. In the group of women, $31.6 \%$ assessed their level of knowledge as low, 34.51\% as average, $32.02 \%$ as hard to determine, and $1.87 \%$ as high. In the group of men, $39.11 \%$ of respondents assessed their level of knowledge as low, 26.4\% - average, 31.98\% - hard to determine, and $2.5 \%$ - high. Statistically significant differences in frequencies were proved (value of chi-squared test 9.85, $\mathrm{df}=3 ; \mathrm{p}=0.0199$ ). A low level of knowledge occurred significantly more frequently in the group of men (value of chi-squared test 7.4; $\mathrm{p}=0.0065$ ).

The next step was an attempt to establish the sources of information about cancer prevention from which the respondents obtained knowledge. $11.74 \%$ of respondents read medical magazines - $15.59 \%$ of women and $7.9 \%$ of men. Significant differences in frequencies were statistically proved by Fisher's 2 -sided exact test $(\mathrm{p}<0.0001)$. The Internet was the source of information for $79.85 \%$ of respondents $-81.29 \%$ of women and $78.42 \%$ of men. $2.48 \%$ used professional literature $-2.08 \%$ of women and $2.89 \%$ of men. A doctor was the source of information for $10.57 \%$ of the respondents $-9.77 \%$ of women and $11.37 \%$ of men. A nurse was the source of information for only $6.52 \%$ of respondents $-7.07 \%$ of women and $5.97 \%$ of men, while the family was a source of information for a mere $1.69 \%$ of respondents $-1.66 \%$ of women and $1.73 \%$ of men. TV was a source of information for $7.10 \%$ of respondents $8.11 \%$ of women and $6.17 \%$ of men. Posters and leaflets were the least frequently used sources of information $(0.72 \%$ of respondents) $-1.25 \%$ of women and $0.19 \%$ of men.

The next part of the research was to check spontaneous knowledge about neoplastic disease, symptoms, methods of treatment and prevention. In the knowledge assessment, the respondents were asked to define neoplastic disease. $13.68 \%$ defined it as cancer, $9.63 \%$ defined it as a serious disease leading to death, while $10.02 \%$ as a serious disease. Neoplastic disease is a growth of tissue and cell proliferation according to $6.31 \%$ of the respondents $-9.15 \%$ of women 
and $3.47 \%$ of men. According to $7.37 \%$ of the respondents, a neoplasm is a tumour $-9.15 \%$ of women, $5.59 \%$ of men. $7.50 \%$ of the respondents believed that cancer is a disease in which the body's cells divide in an uncontrolled way and the newly-formed cancer cells differ from normal tissues (7.69\% of women and $7.32 \%$ of men). According to $13.29 \%$ of the respondents, tumour results from pathological changes of cells, and $3.28 \%$ of the respondents believed that it is a mutation in DNA. Unfortunately, $7.84 \%$ of the respondents believed that a neoplastic disease is an incurable disease (13.95\% of women, $1.73 \%$ of men). Statistically significant differences in frequencies were proved by Fisher's 2-sided exact test $(\mathrm{p}=0.0362)$. When asked how neoplastic diseases are treated, the majority of respondents indicated chemotherapy $(68.21 \%)$, organ transplantation $(2.70 \%)$, radiation therapy (21.97\%), and surgery (18.30\%).

The most frequently mentioned symptom of neoplastic disease was pain $(15.80 \%)$, tumours in various parts of a body (14.45\%), sudden weight loss/emaciation (12.91\%), and weakness (17.15\%). Another question concerned the symptoms that may occur during the treatment of tumour. As many as $51.25 \%$ of respondents believes that a symptom of cancer treatment is hair loss, $18.50 \%$ body weakness, $6.55 \%$ vomiting, and $7.32 \%$ weight loss.

The most frequent spontaneously given cause of neoplastic diseases was smoking (36.61\%), inheritance of the disease (21.77\%) and improper diet (15.03\%), while alcohol was a risk factor for $10.40 \% .9 .83 \%$ of respondents indicated improper lifestyle and $16.18 \%$ UV radiation. However, only $1.93 \%$ of respondents believed that a solarium could also increase the risk of neoplastic disease. Other risk factors mentioned by respondents were as follows: asbestos (3.20\%), bacteria (1\%), lack of physical activity (0.50\%), physical factors $(1.40 \%)$, genetic mutations (4.70\%), addictions (2.70\%), drugs (2.70\%), X-radiation (1.70\%).

Another part of the research was to assess the knowledge of the researched group on methods of detection of neoplastic disease. The most common answer was a medical examination - $37.94 \%$ of the respondents (41.79\% of women and $34.1 \%$ of men). Statistically significant differences in frequencies were proved by Fisher's 2 -sided exact test $(p=0.0132)$. The second most frequent answer was preventive examination, given by $13.4 \%$ of respondents (18.71\% of women and $8.09 \%$ of men). Statistically significant differences in frequencies were proved by Fisher's 2 -sided exact test $(\mathrm{p}<0.0001) .7 .32 \%$ of respondents mentioned mammography (7.9\% of women, $6.74 \%$ of men), while $3.52 \%$ - cytologic examination $(6.65 \%$ of women, $0.39 \%$ of men; statistically significant differences in frequencies were proved by Fisher's 2-sided exact test [p $<0.0001]$ ). Among the more frequent answers given were: magnetic resonance imaging $(4.57 \%$ of women, $7.32 \%$ of men), X-ray examination (97.9\% of women, $10.98 \%$ of men), self-examination (11.43\% of women, $3.85 \%$ of men; statistically significant differences in frequencies were prove by Fisher's 2 -sided exact test $[\mathrm{p}<0.0001])$ and computed tomography ( $4.78 \%$ of women $-10.98 \%$ of men. Statistically significant differences in frequencies were proved by Fisher's 2 -sided exact test $(\mathrm{p}=0.0482)$. Less frequently mentioned tests were a blood test $(4.20 \%)$, urinalysis $(0.80 \%)$, biopsy $(1.70 \%)$, tumour markers $(0.20 \%)$, ultrasound $(4.40 \%)$, IVP $(0.30 \%)$, panendoscopy $(0.50 \%)$, and colonoscopy $(0.30 \%)$.

When asked about the characteristics of melanoma, the researched group most frequently answered that this was a lump on the skin $(50.31 \%$ of women and $44.51 \%$ of men; statistically significant differences in frequencies were proved by Fisher's 2-sided exact test [p=0.0368]). 44.15\% of respondents thought that this was a change bigger than $0.5 \mathrm{~cm},(42.83 \%$ of women, $45.47 \%$ of men). Moreover, $32.22 \%$ of respondents indicated a variety of colours as a feature of melanoma (35.55\% of women, men $28.9 \%$; statistically significant differences in frequencies were proved by Fisher's 2 -sided exact test $[\mathrm{p}=0.0007])$. Other features indicated by respondents were: one colour (30\%), uneven edges (31.60\%), the hardness of a change $(25.70 \%)$, filled with serous fluid (18.40\%), and being movable (16.70\%).

In the further part of the research, the rural inhabitants had to try to identify a carcinogenic factor contained in food. As many as $44.25 \%$ of respondents indicated benzopyrene ( $45.53 \%$ of women, $42.97 \%$ of men). Frequently mentioned risk factors included nitrosamines (30.50\%), aflatoxin (30.50\%), grilled products $(32.70 \%)$, fried food $(39.40 \%)$ and cured products $(21.30 \%)$. No statistically significant differences were observed. Additionally, nitrates and nitrites were indicated by $32.76 \%$ of respondents. Unfortunately, there were also responses that an excess of vitamin $\mathrm{C}$ is a carcinogenic factor $(6.03 \%$ of women, $9.83 \%$ of men; there were statistically significant differences in the frequencies according to Fisher's 2 -sided exact test [ $p=0.0352])$, and as fibre $(2.08 \%$ of women, $5.2 \%$ of men; there were statistically significant differences in the frequencies according to Fisher's 2-sided exact test $[\mathrm{p}=0.0111]$ ).

To assess knowledge of the WHO recommendations regarding the optimal physical activity to prevent neoplastic diseases, the researched group had to indicate the correct frequency of physical activity. The largest group of respondents believed that any physical activity is good $(40.12 \%$ of women and $35.65 \%$ of men). Only $17.24 \%$ of respondents answered correctly by indicating 30 minutes for 5 days a week (15.8\% of women and $18.69 \%$ of men; there were statistically significant differences in the frequencies according to Fisher's 2-sided exact test $[\mathrm{p}=0.0364])$.

Spontaneous assessment of knowledge of the respondents about the biological factors that can cause neoplastic disease proved a significant lack of knowledge. Only 5.9\% of respondents indicated HPV as a risk factor for cervical cancer (women $-8.52 \%$, men $-3.28 \%$; there were statistically significant differences in the frequencies according to Fisher's 2 -sided exact test $[\mathrm{p}=0.0011])$. Unfortunately, there were also responses that HPV was the cause of liver cancer $(0.40 \%)$ or melanoma $(0.30 \%) .3 \%$ of the respondents indicated hepatitis $\mathrm{B}$ and $\mathrm{C}$ as risk factors for liver cancer, while $2 \%$ claimed that it is a cause of leukaemia. Only $1.70 \%$ of respondents claimed that Helicobacter Pylorii may increase the risk of stomach cancer, while $0.58 \%$ of the respondents thought that it is a cause of cervical cancer. Only one respondent indicated Epstein-Barr virus as a risk factor for nasopharynx cancer $(0.10 \%)$, while $0.20 \%$ claimed that HIV is a cause of sarcoma.

Screening tests applied in the early detection of breast cancer was mentioned as follows by the respondents are: mammography $-32.26 \%$ : $41.79 \%$ of women and $22.74 \%$ of men. There were statistically significant differences in the frequencies according to Fisher's 2-sided exact test $(\mathrm{p}<0.0001)$. Breast self-examination was much less frequently mentioned $-2.51 \%: 2.91 \%$ of women and $2.12 \%$ of men, and breast ultrasound $-2.38 \%: 4.37 \%$ of women and $0.39 \%$ of men. There were statistically significant differences in the 
frequencies according to Fisher's 2-sided exact test (much less frequently $\mathrm{p}<0.0001)$.

In the early detection of lung cancer, the largest group of respondents - as much as $16.14 \%$, mentioned chest X-ray: $22.66 \%$ of women, $9.63 \%$ of men; there were statistically significant differences in the frequencies according to Fisher's 2 -sided exact test $(\mathrm{p}<0.0001)$. Other tests mentioned by a small group of respondents were, among others, blood tests (1\%), sputum test $(0.40 \%)$, biopsy $(0.50 \%)$, magnetic resonance imaging (1.70\%), spirometry (1\%), computed tomography $(0.80 \%)$ or ultrasound $(0.70 \%)$. Regarding the diagnosis of stomach cancer, only $8.97 \%$ of respondents mentioned panendoscopy (16.01\% of women, $1.93 \%$ of men; there were statistically significant differences in the frequencies according to Fisher's 2 -sided exact test $[\mathrm{p}<0.0001]$ ), and $4.18 \%$ mentioned ultrasound (6.44\% of women, $1.93 \%$ of men; there were statistically significant differences in the frequencies according to Fisher's 2 -sided exact test $[p<0.0001])$. Other tests mentioned by respondents were biopsy $(0.20 \%)$, colonoscopy $(0.40 \%)$, tumour markers $(0.30 \%)$, X-ray (1.90\%) or computed tomography (0.50\%). In early diagnosis of cervical cancer, cytologic examination was mentioned by $17.77 \%$ of respondents, and much more frequently by women $(30.15 \%)$ than by men $(5.39 \%)$; there were statistically significant differences in the frequencies according to Fisher's 2 -sided exact test $(\mathrm{p}<0.0001)$. A small group also indicates gynaecological examination $(2.75 \%$, including $4.16 \%$ of women and $1.35 \%$ of men; there were statistically significant differences in the frequencies according to Fisher's 2-sided exact test $(p=0.0098)$, and ultrasound $-1.34 \%$ : $2.49 \%$ of women and $0.19 \%$ of men; there were statistically significant differences in the frequencies according to Fisher's 2-sided exact test $(p=0.0012)$. Very poor knowledge about screening tests in early skin cancer detections was shown by the researched group. Dermatological test was mentioned by $4.11 \%$ of the respondents, more frequently by women $(7.07 \%)$ than by men (1.16\%). There were statistically significant differences in the frequencies (Fisher's 2-sided exact test $[\mathrm{p}=0.0056])$. More rarely mentioned were histopathological examination $(0.50 \%)$ and observation $(0.80 \%)$.

In knowledge assessment about the influence of alcohol as a carcinogenic factor, the respondents had to indicate the quantity of wine which is carcinogenic. Unfortunately, as many as $72.40 \%$ of respondents claimed that none of the quantities listed was carcinogenic, while only $4.40 \%$ of respondents provided the correct answer, namely, one glass. The most frequently anti-cancer agent indicated by respondents was beta-Carotene (31.94\%: $30.35 \%$ of women and $33.53 \%$ of men), vitamin C (26.51\%: $24.32 \%$ of women and $28.71 \%$ of men), and well as vitamin E (19.60\%: $14.35 \%$ of women and $24.86 \%$ of men). There were statistically significant differences in the frequencies according to Fisher's 2 -sided exact test $(\mathrm{p}<0.0001)$.

In the final part of the research, the respondents' health behaviours were assessed based on the performance of preventive examinations. Such examinations were performed by only $5.50 \%$ of respondents, cytologic examination by $1.90 \%$, and blood test by $1.40 \%$. The average value of the level of knowledge was $26 \pm 10.48$ (range [1;60], median 25, 95\% CI $[25.09 ; 26.9])$. No statistically significant differences were observed (Mann-Whitney U test, value of test statistics $\mathrm{U}-132237 ; \mathrm{p}=0.1039$ ). Lack of knowledge was noted in $29.48 \%$ of respondents, very low level of knowledge in $42.2 \%$, low in
$17.53 \%$, satisfying in $1.73 \%$, average in $9.06 \%$. A high level of knowledge was not observed. (0.00\%). The average value of the level of knowledge in the respondents, in a family that had not experienced cancer, was $24.95 \pm 10.59$ (range $[1 ; 60])$, median $24.95 \%$ CI $[24.13 ; 25.76])$. In the researched group whose family had experienced cancer, the average value of the level of knowledge was $30 \pm 11.83$ (range [4;70], median $28.95 \%$ CI [28.75;31.26]) - total: $26.69 \pm 11.29$ (range [1;70], median 26.95\%CI [25.99;27.39]). Mann-Whitney U test demonstrated that the value of knowledge in group 1 was significantly lower in comparison to group 2 (value of test statistics - U 86507; p <0.0001). In the group of respondents whose families had not experienced cancer, lack of knowledge concerned $33.54 \%$, very low level of knowledge $-40.09 \%$, low $-17.38 \%$, satisfying $-1.83 \%$, average $-7.16 \%$, while high level of knowledge was not observed (0.00\%). In the group of respondents whose families had experienced a neoplastic disease, the lack of knowledge concerned $22.97 \%$, very low level of knowledge $-34.01 \%$, low level $-25.29 \%$, satisfying $-5.81 \%$, average $-11.34 \%$, and high $-0.58 \%$.

\section{DISCUSSION}

Numerous researches in Poland and worldwide have proved that reduction of risk of tumours is mostly effective by adopting a healthy lifestyle, avoiding exposure to carcinogenic factors and regular performing of screening tests $[12,13]$. The basis for the actions taken is to have reliable knowledge; therefore, pro-social campaigns and prevention me to increase knowledge and abilities in the area of neoplastic diseases prevention are so important $[14,15,16,17,18]$. In neoplastic diseases prevention, theactivities of health service should be focused mainly on the first phase of preventive measures, also called primary prevention. This is 'a set of activities that enhance control over health and improvement of quality of life' through health education and providing recipients with adequate knowledge. 'Health education is featured by high effectiveness and, from the economic point of view, it is the least expensive method for preventing the disease'. According to various data, primary prevention may reduce tumour morbidity even by $75 \%-90 \%$. The task of health promotion in cancer prevention, first of all, is to eliminate or reduce the influence of risk factors by sharing knowledge on these factors and on methods that reduce their influence. Moreover, health promotion creates positive attitudes and health behaviours by elimination of harmful habits and implementation of health advocacy. Actions taken as a part of cancer prevention should concern both those who are healthy and those at increased risk of cancer; health education actions regarding cancers is therefore best started among the youngest. Before the education starts, it is necessary to assess the level of knowledge of the social group in the area of neoplastic diseases and their prevention. Then it is possible to form conclusions based on the research, which should be a starting point for preparing educational programmes $[1,2]$. S. Jeka et al. (2003) have also noticed the necessity to make the patients' knowledge complete, which is the basis of preventive actions that will bear fruit in the future. In their opinion, to form conclusions based on the research and to include them in health security programmes, assessment of the level of knowledge should be taken into account [19]. 
In the presented study, in order to assess the level of knowledge about cancer, a detailed interview questionnaire was applied that made it possible to assess the general knowledge in the area of cancer, which included questions with both spontaneous and prompted answers. According to the study, lack of knowledge concerned $29.90 \%$ of respondents, very low knowledge - 38\%, low - 20.10\%, satisfying $-3.20 \%$, average $-8.60 \%$, while high knowledge only $0.20 \%$ of respondents. Respondents whose families have experienced neoplastic disease were much more aware. The average value of the level of knowledge in the group of respondents whose families had not experienced neoplastic disease was $24.95 \pm 10.59$, while in the group that had experienced cancer, it is $30 \pm 11.83$.

Research by E. Cieślik et al. (2004) on level of knowledge on factors leading to civilization diseases has confirmed the above statement. The level of knowledge of the respondents was low and dissatisfying: only $47.50 \%$ of respondents obtained $50 \%$ of the correct answers [20]. Research by M. Pyd et al. (2000) conducted in Białystok, north-east Poland, proved the lack of knowledge on factors increasing cancer risk, as well as a preference for unconventional treatment methods among the majority of respondents [21]. Research conducted by M. Florek-Łuszczki (2010) indicate that the level of knowledge of female rural inhabitants about breast cancer risk factors was very low. Almost $80 \%$ of them e admitted to having no knowledge in this matter [3].

US National Academy of Sciences research shows that dietary factors and diet mistakes are the reason for the majority of tumours. To a large extent, this results from change of lifestyle, mainly reduction of physical activity, increased consumption of highly processed foods, and the use of stimulants. Risk factors connected to lifestyle are changeable and may therefore play a significant role in primary prevention. Elimination of risk factors by reduction of calories in diet, maintaining proper body weight, reducing carbohydrate and alcohol intake, regular physical activity of moderate intensity, may predispose to lower risk of cancer $[22,23]$.

M. Dziubak et al. (2011) have proved that $97.60 \%$ of the respondents believe that smoking is associated with risk of cancer, alcohol abuse is associated with risk of tumours by $54.40 \%$ of the researched, while $28.80 \%$ of respondents claim that overweight and obesity also may be a tumour risk factor. According to the respondents, in the prevention of diseases, a proper diet is of great importance in the form of reduction of animal fats (69.60\%), canned and processed products (55.20\%). Low physical activity is a cancer risk factor, according to $33.60 \%$ of respondents. Among the behaviours associated with risk of cancer, the respondents mention also risky sexual behaviours (46.40\%), infections $(54.00 \%)$, excessive exposure to sun rays $(74.40 \%)$, and the use of solariums (81.60\%). The responders were aware that preventive medical examinations are important in neoplastic disease prevention. The tests they mention wre: mammography (53.60\%), cytologic examination (40.00\%), breast self-exam (11.20\%), breast ultrasound (8.80\%) and colonoscopy (5.60\%) [24].

In the presented study, the most frequently mentioned risk factors were: smoking (36.61\%), improper diet (15.03\%) and improper lifestyle (9.83\%). Completely different results in the assessment of knowledge about health behaviours were obtained by E. Krajewska-Kulak et al. (2011), who stated that knowledge about the rules of use of solariums, healthy tanning and the negative effects which may result, is unsatisfactory. According to the conducted research, $60 \%$ of respondents did not know what 'skin phototype' was and that tanning is a solarium was more dangerous than tanning in the sun for $29.1 \%$ of the respondents. The majority of respondents $(60 \%)$ did not see any reason why children and teenagers should not benefit from solariums. $47.3 \%$ of the respondents could not enumerate negative effects of UV radiation [67].

The current study shows that UV radiation is a risk factor according to $16.18 \%$ of the respondents, while solariums only for $1.93 \%$ of all respondents. What is also disturbing is the fact that the majority respondents were unaware of this risk factor and did not do undertake preventive tests.

In 2009 in the United States, S. Smith et al. conducted a very interesting study in which they attempted to assess the impact of different types of messages about cancer originating from different sources on the health behaviours of a group of female respondents. During the study, four types of messages were communicated: early detection, general information on cancer, cancer treatment and cancer prevention. The information came from media, friends, family, doctor and nurse. According to the study analysis, the media were the main source of information for all four knowledge categories (35.5\%), followed by friends (22.2\%) and family members $(21.6 \%)$, while doctor and nurse were the source of knowledge for $15.2 \%$ of the respondents. The information that made the greatest impression onj the respondents was that concerning early detection $(37.3 \%)$, while the poorest knowledge concerned prevention (6\%). The researchers concluded that although knowledge passed on by the media was very wide ranging, interpersonal communication had the greatest impact on health behaviours. Information from doctors and nurses were more important in further preventive actions due to their high credibility [276]. This is why it seems that authors' actions are reasonable and necessary, especially due to scientific reasons given above.

The study by Florek-Łuszczka (2010) has shown that women living in villages derive knowledge on breast diseases mainly from brochures and leaflets. Only every fifth respondent stated that the knowledge she had came from a gynaecologist [3].

According to the presented research, the most frequently used source of knowledge is Internet (79.85\%), while a doctor was the source of information for $10.57 \%$ of respondents, and a nurse for $6.52 \%$.

\section{CONCLUSIONS}

1. Every third respondent declared having experienced neoplastic disease in the family, which most frequently concerned the grandparents.

2. In knowledge self-assessment, every third respondent declared a low or average level of knowledge.

3. The most frequently used source of knowledge was the Internet, and much more rarely a doctor or a nurse.

4. The media should be used to impart credible and scientific knowledge on neoplastic diseases and, above all, health education should be made obligatory by health services.

5. Very few respondents could enumerate the tests applied in the early detection of cancer. 
6. A negligible percentage of respondents performed screening tests for cancer.

7. Women were proved to have a higher level of knowledge than men.

8. The respondents who had experienced cancer in their families had a significantly higher level of knowledge.

\section{REFERENCES}

1. Chybicka A. Progress in diagnostics and cancer treatment in children. Family Medicine \& Primary Care Review. 2004; 6(1): 309-315.

2. Chybicka A, Kazanowska B. The most frequent diagnostic errors in children hematology and oncology. Family Medicine \& Primary Care Review 2003; 5(3): 347-355.

3. Florek-Łuszczki M. Level of knowledge of breast cancer risk factors and prophylactic principles among female rural inhabitants. Medycyna Ogólna 2010; 16(XLV), 3: 406-415.

4. Lewandowska A. Children from families with cancer. Polish Oncology 2007; 10(4): 169-172.

5. World Health Organization Regional Office For Europe: Social inequalities in health in Poland. World Health Organization, Denmark 2011; 97-98.

6. Lewandowska A. The children's knowledge about tumours. Polish Oncology 2007; 10(4): 173-177.

7. Kornafel J (ed.). Cervical tumours. Warszawa: Centrum Medyczne Kształcenia Podyplomowego, 2011.

8. Khan K, Curtis CR, Ekwueme DU, Stokley S, Walker C, Roland K, Benard V, Saraiya M. Preventing Cervical Cancer. Cancer 2008; 113(10 suppl): 3004-12.

9. Bożek J. Tumours of childhood. Warszawa: PZWL, 1989.

10. Chybicka A. Nourishment, physical activity and cancer in children. Medical News 2003; 72(4): 327-329.

11. Wydro D. Early detection of a cancer is a chance. accessed: www. mediweb.pl.
12. Adamowicz K, Zaucha JM, Majkowicz M. Assessment of knowledge on cancer prevention of patients from Breast Diseases Prevention Clinic. Journal of Oncology 2011; 61(5): 449-456.

13. Jokiel M, Bielska-Lasota M, Kraszewska E. Knowledge and health behaviours of women regarding breast cancer prevention in 1998-2002. Przegląd Epidemiologiczny 2003; 57: 521-30.

14. Andruszkiewicz A, Banaszkiewicz M (ed.). Health promotion for students of bachelor's degree in nursing. In: Teoretyczne podstawy promocji zdrowia, vol 1, Lublin: Wydawnictwo Czelej, 2008, p. 70-71.

15. Gotlib J, Rebandel H. Preliminary evaluation of the perception of pro-health attitudes of medical staff and their own health behaviours in perception of the students of the Medical University of Warsaw. Pielęgniarstwo XXI wieku 2009; 3(28): 38.

16. Denys A, Fiedotow M. Health culture among students. Part I. Lifestyle. Acta Clinica et Morphologica. 2005; 5.

17. Lewko J, Politynska-Lewko B, Sierakowska M, Krajewska-Kułak E. Health behaviours among students of nursing. Annales Universitatis Mariae Curie-Skłodowska, Lublin-Polonia, vol. LX, suppl. XVI, 283, SECTIO D: 2005 .

18. Porębiak MI. Facts and myths on neoplastic diseases. Psychoonkologia 2008; 2: 52-57.

19. Godlewski D, Wojtyś P, Bury P. Vitamin C and malignant tumours. Review paper. Współczesna Onkologia 1999; 3(5): 183-187.

20. Cieślik E, et al. Youth's level of knowledge on diseases caused by improper diet. Bromat Chem Toksykol. 2004; Suppl.: 23-29.

21. Pyd M, Lachowicz M, Chodynicki S. Knowledge on neoplastic disease among secondary schools' students. Otolaryngologia Polska 2000; LIV(Suppl. 31): 301-304.

22. Milner JA. Diet and Cancer: Facts and Controversies. Nutr Cancer 2006; 56: 216-224.

23. Doll R, Peto R. The Causes of Cancer: Quantitative Estimates of Avoidable Risk of Cancer in the United States Today. J Natl Cancer Inst. 1981; 66: 1191-1308.

24. Dziubak M, Dziedzic M, Mierzwa A. Knowledge of secondary school students on lifestyle's influence on cardiovascular and neoplastic diseases and their health behaviours. Przegląd Medyczny Uniwersytetu Rzeszowskiego i Narodowego Instytutu Leków w Warszawie, Rzeszów 2011; 2: 224-238. 